\title{
Investigation of Barriers and Factors Affecting the Reverse Logistics of Waste Management Practice: A Case Study in Thailand
}

\section{Sumalee Pumpinyo * and Vilas Nitivattananon}

Urban Environmental Management Field of Study, School of Environment, Resources and Development, Asian Institute of Technology, Pathumthani 12120, Thailand; E-Mail: vilasn@ait.asia

* Author to whom correspondence should be addressed; E-Mail: Pumpinyo@ait.asia or fecosup@hotmail.com; Tel.: +66-81-443-0715.

External Editor: Vincenzo Torretta

Received: 8 August 2014; in revised form: 19 September 2014 / Accepted: 22 September 2014 / Published: 13 October 2014

\begin{abstract}
Economic growth in developing countries accelerated waste generation, and Thailand also is experiencing issues related to increased waste generation and improper waste management. The country's domestic waste utilization is only $20 \%-26 \%$. Efficient waste management and increased quantity of waste utilization is possible only by overcoming problems and constraints in reverse logistics (RL) systems in Thailand. To address these issues and constraints, this study aims to focus the investigation on the current practices in the RL systems. The study was conducted in Bangkok and its vicinity. An integrated approach of qualitative and quantitative methods was employed to investigate the systems' and stakeholders' characteristics and to explore the factors influencing and constraining RL practices. Data were gathered through: (1) existing literature and in-depth interviews of key stakeholders involved in RL; and (2) a questionnaire survey of 98 managers of separation centers (SCs) probing their practices and studying the factors influencing those practices. The findings showed that RL systems can be separated into three levels, i.e., downstream, middle stream and upstream. SCs are key stakeholders in RL of waste management, and they collect waste from downstream, manage waste in a systematic way and send it upstream. The factors influencing and the barriers in the flow of recyclable waste are related to environmental, economic and social aspects. The analysis shows that waste managed by a cooperative-like franchise of SCs perceived that their practices were more efficient than those of a non-franchise practices. Additionally, these SCs have more
\end{abstract}


bargaining power with waste buyers and sellers to set prices in the RL system. The constraints in RL practice are related to finance, market, labor, management/technology and legal issues.

Keywords: reverse logistics; separation center; waste franchise; waste management

\section{Introduction}

The poor state of solid waste management in cities of developing countries is fast becoming a social and environmental problem. In this regard, there has been continuous promotion of recycling-oriented practices to ensure sustainable growth by reducing the consumption of natural resources and lessening environmental burdens. Reverse logistics (RL) is the process of planning, implementing and controlling an efficient and cost effective flow of raw materials, in-process inventory, finished goods and related information from the point of consumption to the point of origin for the purpose of recapturing value or proper disposal [1]. The first known definition of RL was by the Council of Logistics Management (CLM) in the United States during the early 1990s. The role of logistics is in terms of production returns, source reduction, materials reuse, recycling and replacement, waste disposal, clean up, repair and remanufacturing [2]. Reverse flow characteristics had uncertain paths, and RL channels might take several forms depending on waste size and volume, distance from markets, stakeholders and their experience [3].

Waste quantities are linked to economic activity, resource consumption and economic growth. Economic growth in Southeast Asian countries has driven urban growth, which is approximately 6\%-8\% per year. In Thailand, waste generation rates are relatively high as a result of economic development, industrialization, consumer behavior and an affluent urban population. According to Thailand's Pollution Control Department report (PCD), the total amount of solid waste generated per day in the nation grew from roughly 34,492 tons in 1995 to 41,064 tons in 2009 , and increased to 43,779 tons in 2011 or 16.62 million tons per year. Recycling has been broadly promoted for several decades. However, the recycling rate in Thailand is rather low. Only approximately 3.9 million tons (26\%) of over 16 million tons of annual generated waste is being recycled [4], whereas it is estimated that the potential recyclable waste in Thailand is as high as $40 \%-60 \%$ [5]. Excessive solid waste generation without proper treatment caused a number of negative impacts and became an emerging social and environmental concern. Furthermore, some wastes are imported to be mixed with virgin raw materials for the production of new materials. For example, more than one million tons of recyclable paper is imported annually for the purpose of paper production [6]. This reveals a problem with RL of waste management in Thailand.

The RL of waste management in Thailand involves many stakeholders. Initial RL implementation in Thailand has been done by an informal sector [7]. There is little guidance on the implementation of good practices. For a better understanding of RL systems in Thailand, the objective of the study was to investigate the current practice of RL of waste management in Thailand. This was to learn which are the drivers pushing RL practices and the barriers to their practice. 


\section{Review of the Literature}

Reverse logistics was defined by [8] as "a term that refers to the role of logistics in production returns, source reduction, recycling, materials substitution, reuse of materials, waste disposal, refurbishing, repair, and remanufacturing". This is for the purpose of recapturing values or proper disposal, as well as integrating environmental and economic considerations.

Fleischmann et al. [9] classified product recovery networks based on their main differences following the degree of centralization, number of levels and links with other networks. Product recovery networks could be separated into three types and those are: (1) bulk recycling networks; (2) assembled-product remanufacturing networks; and (3) reusable networks. The authors of [10] divided recovery/disposable options into the following eight types: direct reuse/resale, repair, refurbishing, remanufacturing, cannibalization, recycling, incineration and disposal in landfill. Each of the product recovery options involves collection followed by a combined inspection/selection/sorting process, then re-processing or direct recovery takes place and, finally, redistribution [11]. Reverse channel members may perform a different set of logistical functions, including collection from the consumer, sorting, storage, transport, compaction or densification and communication or intermediate processing of recyclables into a usable form. The authors of [12] grouped reverse logistics research from 1998 to 2006 into empirical, theoretical, conceptual and mathematical categories. They also present an interesting representation of the relations between the functions, activities, inputs, outputs, mechanisms and overall system perspective.

As an example of RL of waste recycling, [13] considered the design of a recycling network for carpet waste to design a European network for recycling of this waste. Attention was paid to the technical, logistic, organizational and economic aspects of such a network and focused on the design of its logistic structure. They proposed a continuous location model that used a linear approximation. The results obtained from the model suggested that networks for reusing carpet waste can be economically viable, though a number of tasks were involved, including identification, sorting, separation and compaction. Logistic networks for product recovery and recycling were characterized by [9]. They considered recycling of steel by-products and carpets. Material suppliers play an important role in these networks. Moreover, investment costs turn out to be very crucial in all of the recycling networks, which are highly vulnerable to uncertainty concerning a reliable supply volume. Moreover, cooperation within sectors may be a way to ensure high processing volumes. The technical feasibility of material recycling was not critically dependent on the quality of the collected goods. However, input quality may be a major cost determinant, e.g., by influencing the purity of output materials.

Factors influencing the readiness of households to segregate plastic and non-plastic waste were identified by [14]. Their results show that most respondents agreed that plastic recycling would contribute to a cleaner city. The respondents were willing to separate the waste if there were collection companies that paid them for their plastic waste, even at a low price. A programming approach for a plastic recycling system in Thailand was developed by [15]. In it, plastic waste was a big issue and the amount recycled very low. Due to high investment costs for recycling, the majority of plastic waste was simply burned or disposed in landfills. The study used the MIGP model to analyze the relationship between cost reduction, increased amounts of recovered plastic and its utilization in recycling processes. The results show the need to decrease the total cost of high quality recyclables for the plastic materials 
desired. Figure 1 summarizes the flow of RL. It starts with products going back into the supply chain or calling for recovery or value reclamation.

Figure 1. Reverse and forward logistics flow.

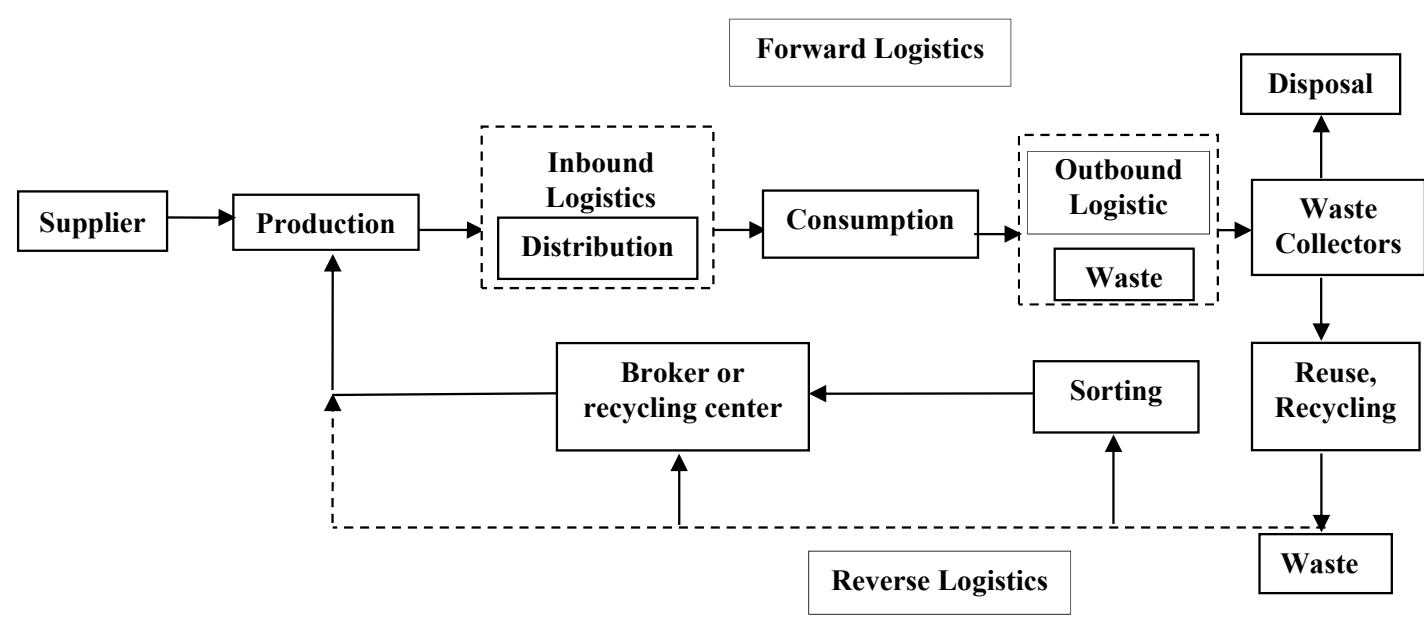

\section{Research Concept and Methodology}

\subsection{Research Concept}

The concept of RL was used to investigate RL current practice in Thailand and to find the factors influencing RL and its barriers in urban areas. The potential factors were determined from a literature review and key informant interviews. In order to achieve the proposed objectives, the study used a mixed research approach integrating qualitative and quantitative methods.

\subsection{Research Methodology}

The methodology of this study consisted of the following. First, the study began with interviews of SCs experts, their customers and people from industries that purchase recyclable waste. To examine the source of waste, we have interviewed the personnel from a school garbage bank, community garbage bank, offices and industries. To gain end user perspective, we interviewed personnel from paper processing, plastic and glass industries. During this step, our goal was to elucidate the characteristics and stakeholders of RL systems within the study area. From key informant interviews and a literature review, the factors influencing and constraining RL practices were identified. In this way, efficiency in the practice of cooperative-like franchise and non-franchise businesses was compared. In Thailand, separation centers (SCs) are key stakeholders in return processes. SCs collect waste from its source and manage it through the separation process before sending it to a recycling center or end user. SCs in Thailand separate waste in a cooperative-like franchise and non-franchise businesses. Keeping in view different types of SCs, the first hypothesis of this study was that the performances of different types of SCs in RL are significantly different based on variable RL practices adopted by SCs. Secondarily, it was also hypothesized that a cooperative-like franchise is more efficient at performing in RL practice compared to a non-cooperative one. The study investigated waste return. This paper discusses the driving forces and the constraint of their practices. The potential drivers and barriers were determined from 
a literature review and key informant interviews. Figure 2 shows the methodological framework of this study.

A questionnaire survey was used to identify the factors influencing and constraining these RL practices. Lessons learned are presented with conclusions and recommendations. The questionnaire was divided into three parts. The first part probed for general information. The second part inquired about managers' opinions of influential factors, and the final part was used to determine barriers to RL practice. It included open-ended questions to elicit suggestions on RL practice improvements and to encourage the participants to give meaningful input based on their experience and knowledge to increase the value added to the RL practice. The factors on the questionnaire were tested for reliability and internal consistency as accurate indicators [16]. The internal consistency was estimated using Cronbach's alpha as a reliability coefficient. A Cronbach's alpha of 0.868 was obtained, indicating a highly reliable instrument.

Figure 2. Methodological framework. RL, reverse logistics.

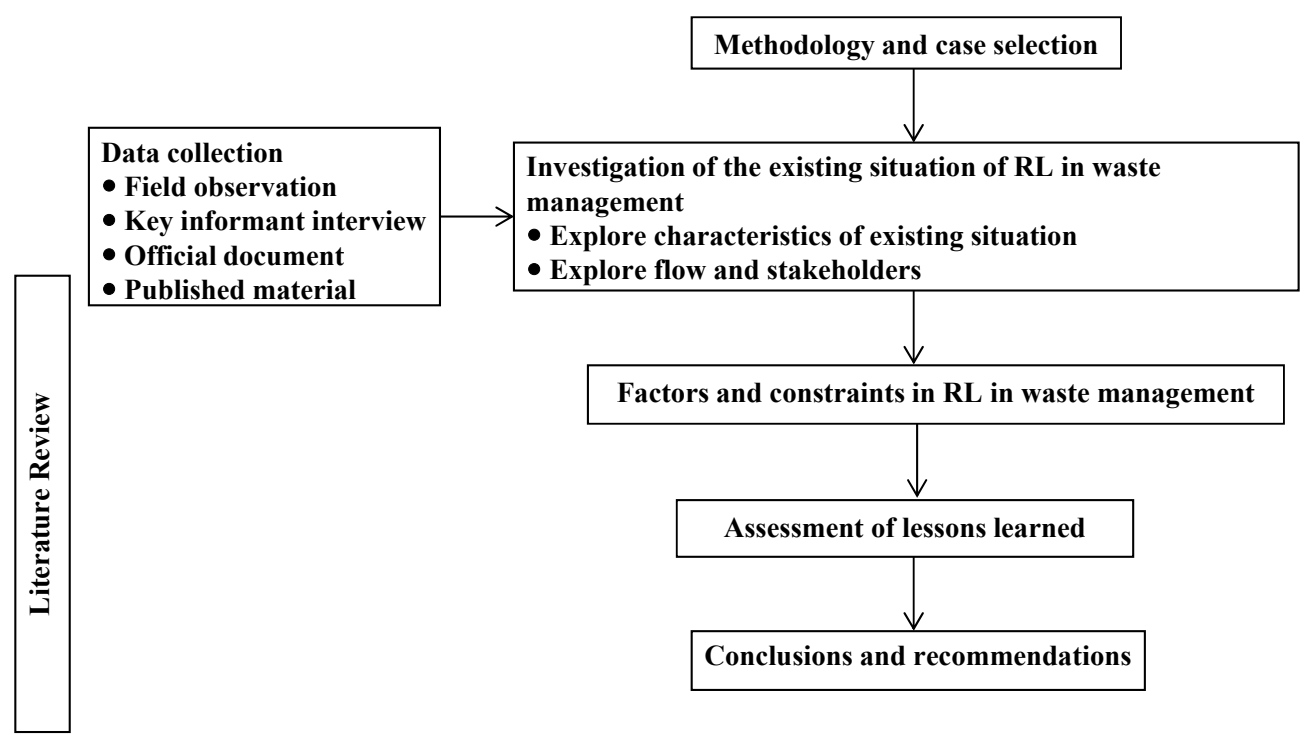

\subsection{Data Collection and Analysis}

For primary data collection, a qualitative method was used for key informant interviews, site visits and observations. For the quantitative methodology, a questionnaire survey was used to collect opinions of personnel working in SCs about key factors that are important in RL practice. The study area was in metropolitan Bangkok and its vicinity. In Bangkok, the amount of municipal solid waste (MSW) generated daily was 8766 tons or $22 \%$ of the nation's total waste. MSW generation is concentrated in Bangkok and the urban areas of Thailand. This area is the center of economic growth and development. This region contains 970 separation centers [17], and the sample size was calculated with a $10 \%$ allowable error [18], making the required sample size 97; however, in this study, 98 sampled questionnaires were completed. The summery is given in Appendix A1.

Questionnaire responses used a five-point Likert scale implemented to assess respondents' opinions of RL practices. The variables that influenced RL practices were classified into environmental, economic and social aspects. Respondents' opinions are a measure of how SCs perceive the priority of each factor. In the fieldwork, measurement of respondents' opinions was done by asking the perception of representatives of SCs businesses about the influence of each factor probed in the questionnaire. 
The respondents answered, on this five-point Likert scale, indicating whether they were very poor, poor, moderate, good or very good by assigning weights. Hence, the magnitude of influence of each factor was different due to the individual characteristics of the SCs. Then, a weighted average index (WAI) was applied to analyze respondents' opinions. Following [19], WAI has been computed using Equation (1).

$$
I=\frac{\sum s_{i} f_{i}}{N}
$$

where, $\mathrm{I}=\mathrm{WAI}$, such that $0 \leq I \leq 1, s_{i}$ denotes the scale value at the $\mathrm{i}$-th priority ranging from very poor, poor, moderate, good to very good, $f_{i}$ denotes the frequency of the i-th priority and $\mathrm{N}$ is equal to the total number of observations $=\sum f_{i}$. WAI was used to transform the opinions of respondents from a nominal scale (very poor-very good) into numeric scores. The scores were classified into five levels by providing weights, such as: $0-0.20=$ very poor; $0.21-0.40=$ poor; $0.41-0.60=$ moderate; $0.61-0.80=$ good; $0.81-1=$ very good. Additionally, the $t$-test was applied for a comparison of WAI mean values between the different RL practices at a 95\% confidence level ( $p$-value $<0.05)$. Content-based analysis was used in the qualitative approach.

\section{Results of the Study}

\subsection{Investigated Existing Situation of RL Practice}

The findings from in-depth interviews with the focus groups revealed the nature of material flows in waste management. RL channels of waste streams in Thailand and stakeholder are shown in Figure 3. They can be divided into three levels. The lowest level, or downstream, consists of those who generate waste, such as municipalities. It also includes households and businesses. Factors influencing the rate of collection from the source of waste are the cooperation of NGOs, transportation costs, availability of skilled operators to do source separation and awareness of solid waste management problems [20]. The middle level, or middle stream, is quite diverse. The upstream consists of end users that use recyclable waste as raw material in their production processes. Waste may be collected by municipalities. Alternately, scavengers and waste pickers may collect waste for resale. Mixed-waste may also be delivered by SCs, known as junk shops, as well as second and third-party dealers. Third-party dealers are medium-sized SCs. They require some investment in machinery. Their suppliers are households, industries and scavengers who collect wastes using carts and pick-up trucks. Second-party dealers are large separating centers that collect waste from third-party dealers, small separating centers and industries. The center sends the wastes to recycling centers or export facilities. SCs can be further classified as franchise and non-franchise types. SCs are quite important in the flow of waste, and they are responsible for cleaning, storing and compacting waste to meet volume requirements before the waste is exported or transported to the end users. The end users need a continuous supply of recyclable waste, waste cleanliness and correct sorting of waste to use it as the raw material in their production processes. Incorrect sorting of waste increases their cost through internal logistics costs in the form of a flow of incorrect material and maintenance costs, as this may cause the disorder of the machines [21]. 
Figure 3. Reverse logistics channels in Thailand.

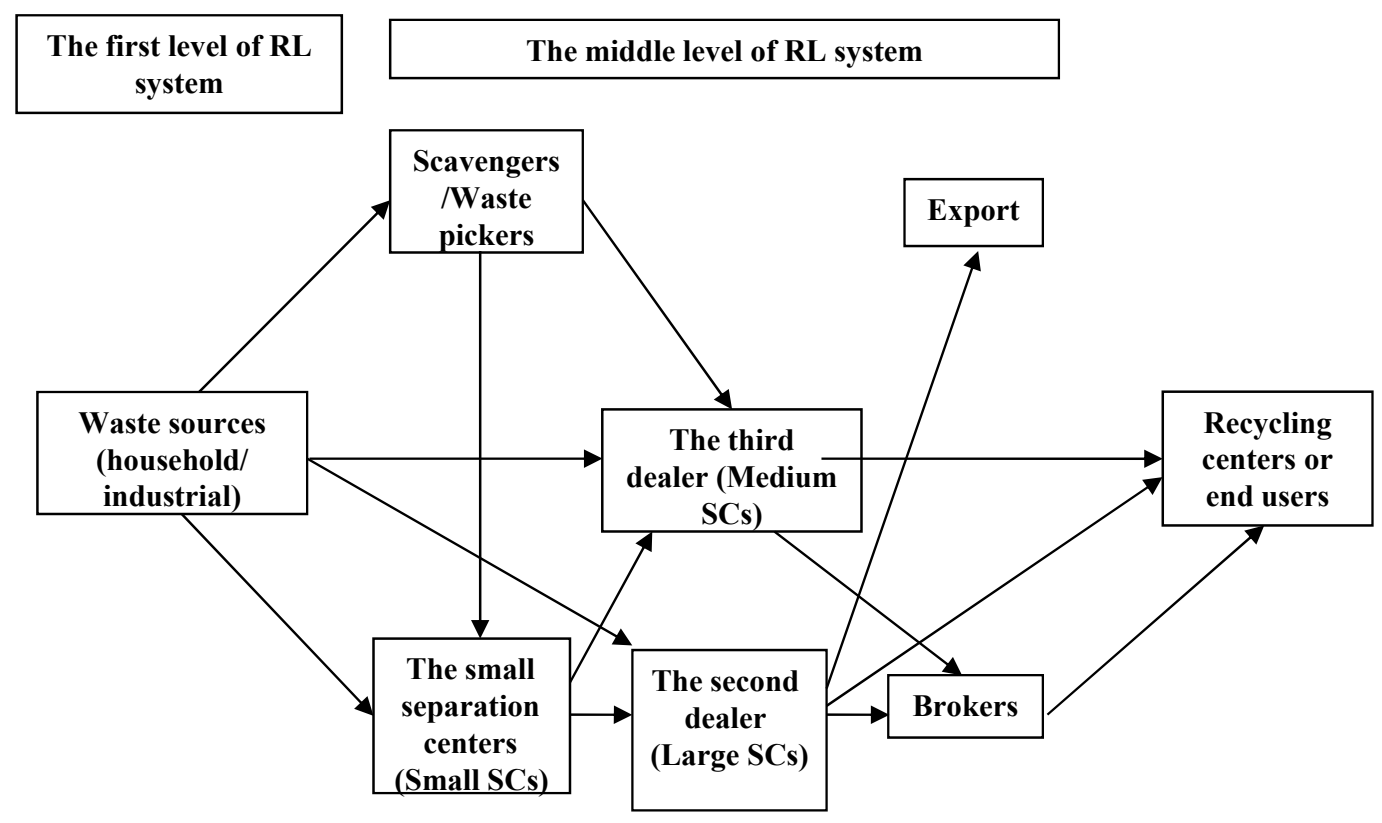

\subsection{Investigated Factors Influencing and Barriers to RL Practice}

\subsubsection{The Potential Factor Influencing and Constraint of RL of Waste Practice}

$\mathrm{RL}$ is well-known for its use in optimizing resources, which possibly minimizes the costs of returned materials derived from negative impacts [2]. Indeed, recovery costs are essential to running a business in that recycling practices generally entail market competition in terms of the primary materials' price and quality [22]. Product recovery management is vital to improve the cost-effectiveness of firms, which hinges on their capabilities [10]. Increasing costs substantially influences RL performance [23] as the total cost of RL comprises collection, inventory, transportation, and storage costs. Waste management systems should consider sustainability from social, economic and environmental viewpoints [24]. Clean outputs are a way to improve environmental performance. Investment in technology is necessary for clean production. Innovation and technology require highly skilled people [25]. Sustainable development simultaneously requires resource conservation, environmental protection and social, as well as economic development [26]. Use of RL concepts provides a good strategy to economically reduce and reutilize waste. Trust is another factor that positively affects successful RL, but only if the relationship involves a strong commitment to customers [27].

RL practices greatly improve a firm's performance and productivity by means of customer satisfaction [28]. In this respect, all businesses should gauge their logistic performance to increase revenues and reduce operating costs, and then, shareholder value will increase [29]. Logistics knowledge is essential for business performance [30]. Therefore, the firms' capabilities must be continually developed in terms of innovative logistics to optimize the RL system and diminish the uncertain characteristics of RL activities [31]. Additionally, internal and external impacts on retail chain organizations and their performance should be meaningfully regarded as discussed by [25], who claimed that all firms tend to be influenced by internal competitiveness, clean manufacturing, recycling and reuse, social equality and efficient human resource management. Eventually, information systems and 
physical infrastructure may impact the success of the reverse supply chain activities [32]. An effective reverse logistics infrastructure and financially viability must be sustainably provided to support recovery practices [15]. From the study of [33], key barriers are separated into four categories. They are: (1) management practices evident from a lack of reverse logistics expertise and low commitment; (2) financial issues involving a lack of initial capital and funds for systems to monitor returns; (3) policy issues with a lack of enforceable laws and supportive economic policies; and (4) the lack of infrastructure for monitoring returns.

$\mathrm{RL}$ of waste is a complicated and sophisticated system, since it involves environmental, economic and social aspects. It is necessary to consider environmental aspects in order to reduce environmental damages. Furthermore, a system that is not economically justifiable will not be successful in the long run. Moreover, a system for waste management will not work if it is not accepted and used by citizens; therefore, the social aspects are imperative. The economics aspect is also important in the flow of waste management, as it finds the methods and ways to provide incentive through increasing benefit and reducing cost.

\subsubsection{Factor Influencing RL of Waste Management Practices in Thailand}

From the study, SCs are key stakeholders in RL of waste. The characteristics of the flow of waste of 98 SCs are shown in Table 1.

Table 1. Characteristics of the flow of waste of separate centers (SCs).

\begin{tabular}{ll}
\hline \multicolumn{1}{c}{ Detail } & \multicolumn{1}{c}{ Proportion (\%) } \\
\hline Recyclable waste in SCs & $\begin{array}{l}\text { Metals }(29 \%) \text {, paper }(26.6 \%) \text {, plastic }(23.2 \%), \\
\text { glass }(20.9 \%) \text { and other materials }(0.3 \%)\end{array}$ \\
\hline \multirow{2}{*}{$\begin{array}{l}\text { Households }(23.6 \%) \text {, industries }(22 \%), \text { offices }(16.7 \%), \\
\text { scavengers using pickup trucks }(15.7 \%), \text { junk shops }(10.2 \%), \\
\text { scavengers using carts }(7.5 \%) \text { and other sources }(4.3 \%) .\end{array}$} \\
$\begin{array}{ll}\text { Channels for selling } \\
\text { recyclable of SCs }\end{array}$ & Recycling centers $(56.6 \%)$, brokers $(42.7 \%)$ and other channels $(0.7 \%)$ \\
Machine in waste & Cutting metal $(22.2 \%)$, compacting paper $(20 \%)$, compacting metal \\
separation & $(15.9 \%)$, compacting plastic $(10.1 \%)$ and other purposes $(31.8 \%)$
\end{tabular}

Furthermore, the model RL of waste management in Thailand can be classified into two types. The first is regular SCs or non-cooperative forms of the business, while the other is a cooperative-like franchise. To investigate factors influencing and barriers to these practices, the study collected information from 74 people working in non-franchise SCs and 24 from cooperative-like franchises (the number of franchised SCs is less than non-franchised). The potential factors influencing and barriers were determined from interviews of key informants coupled with information derived from published literature $[25,27,28,32]$.

As can be seen in Table 2, the perception of factors influencing non-franchise SCs was lower than franchise SCs in some areas, especially waste management performance $(\mathrm{WAI}=0.6721)$ and economies of scale (WAI = 0.7151). Managers of non-franchise SCs accepted that their businesses need greater investment in machinery and knowledge, as well as the need to improve workers' skills. The authors 
of [25] found that innovation, technology and specific skills were required for this work. However, managers' opinions about practice of non-franchise and franchise SCs were indifferent in terms of cleanliness of recyclable wastes (WAI $=0.8243$ and 0.8000 , respectively) and satisfaction with waste separation at the sources (WAI $=0.7892$ and 0.7333 , respectively). Franchise SCs have more credibility in the eyes of customers (WAI $=0.9083$ ).

Franchise SCs' operations have better practices when adapting to business change due to economies of scale $(\mathrm{WAI}=0.8083)$. Economies of scale also provide for access to transportation networks $(\mathrm{WAI}=0.8417)$. Cost reductions are achieved due to the use of more fully-loaded trucks. Business plans can be more flexible (WAI $=0.8083$ ), and the turnover rate of saleable material is increased $(\mathrm{WAI}=0.6974)$ when more waste is processed. Managers of franchise SCs perceived their practice as higher in social involvement than did non-franchise managers ( $\mathrm{WAI}=0.9333)$. They perceived that they were well known in the waste management business through socialization (WAI $=0.8833$ ). This was a result of community training programs on waste recycling that they offered.

Table 2. Descriptive statistical analysis of perception of RL practice in waste management.

\begin{tabular}{|c|c|c|c|}
\hline & \multirow{3}{*}{ Criterion } & \multicolumn{2}{|c|}{ Weighted average index } \\
\hline \multirow{2}{*}{ Aspects } & & Non-Franchise & Franchise \\
\hline & & $(n=74)$ & $(n=24)$ \\
\hline \multirow{7}{*}{ Environmental } & Capability in waste management practice ${ }^{*}$ & 0.6721 & 0.7833 \\
\hline & - Level of cleanliness of recyclable wastes & 0.8243 & 0.8000 \\
\hline & - Highly skilled workers * & 0.6378 & 0.7333 \\
\hline & - Technological level * & 0.5541 & 0.8167 \\
\hline & Environmental concern $*$ & 0.7932 & 0.8917 \\
\hline & $\begin{array}{l}\text { - Perception level of entrepreneurs on } \\
\text { environmental impacts }\end{array}$ & 0.7486 & 0.9250 \\
\hline & $\begin{array}{l}\text { - Mitigation of noise, smells, and other } \\
\text { disturbances to neighborhood * }\end{array}$ & 0.8378 & 0.8583 \\
\hline \multirow{9}{*}{ Economic } & Economies of scale $*$ & 0.7151 & 0.7850 \\
\hline & $\begin{array}{l}\text { - Increase in the amount of sales and purchases } \\
\text { this year when compared to last year * }\end{array}$ & 0.7595 & 0.7667 \\
\hline & - Adaptation to change in business * & 0.7486 & 0.8083 \\
\hline & - Access to transportation network * & 0.7351 & 0.8417 \\
\hline & - Having business plan * & 0.6973 & 0.8083 \\
\hline & - Increase in turnover rate * & 0.6351 & 0.7000 \\
\hline & Customer satisfaction $*$ & 0.7770 & 0.8583 \\
\hline & - Trust in product and service quality * & 0.8054 & 0.9083 \\
\hline & $\begin{array}{l}\text { - Waste is sufficiently separated at a } \\
\text { generation source }\end{array}$ & 0.7892 & 0.7333 \\
\hline \multirow{3}{*}{ Social } & Relationship within RL network & 0.7662 & 0.9083 \\
\hline & - Level of social involvement * & 0.7351 & 0.9333 \\
\hline & - Well-known in retail customer & 0.7973 & 0.8833 \\
\hline
\end{tabular}

Notes: Weighted average index: $0-0.20=$ very poor; $0.21-0.40=$ poor; $0.41-0.60=$ moderate; $0.61-0.80=$ good; $0.81-1=$ very good; * the difference in the means from the two groups was significant $(p<0.05)$. 
Table 3 presents some barriers on practices experienced by SCs. These were identified through interviews of key informants. It is seen that non-franchise SCs businesses have more limitations in terms of finance/accounting, market competition, and labor.

Table 3. Descriptive statistics of barriers to RL practice.

\begin{tabular}{lcc}
\hline & \multicolumn{2}{c}{ Weighted average index } \\
\hline \multicolumn{1}{c}{ Constraints } & Non-Franchise SCs & Franchise SCs \\
\hline Finance/Accounting & 0.81 & 0.50 \\
Market competition & 0.78 & 0.69 \\
Management/Technology & 0.51 & 0.46 \\
Labor & 0.76 & 0.69 \\
Regulation/Government policy & 0.39 & 0.32 \\
\hline
\end{tabular}

Notes: Weighted average index: $0-0.20=$ very poor; $0.21-0.40=$ poor; $0.41-0.60=$ moderate; $0.61-0.80=$ good; $0.81-1=$ very good.

Figure 4 is a diagrammatic representation of the main barriers experienced by SCs in RL practice. These barriers fall into several categories. The first is financial difficulties. Individual firms within the informal sector, especially non-franchise SCs, are considered poor risks by financial institutions/banks. This makes it difficult for them to obtain loans to purchase machinery or make an investment that would achieve economies of scale. Market competitiveness is another barrier. There are many small SCs that separate waste manually. Each has a very small market share, and they must compete against all other $\mathrm{SCs}$ on the basis of the prices for materials. From labor issues, non-franchise SCs rely on temporary workers, since the work environment is very unpleasant. Constant employee turnover has caused instability in a number of companies. Non-franchise SCs lack information, knowledge and modern technology to compact waste. Hence, they are unable to reduce their transportation costs. Regarding taxation, there are multiple taxes collected by the government and a lack of government supportive economics policies.

Figure 4. Summary of barriers affecting sustainable performance.

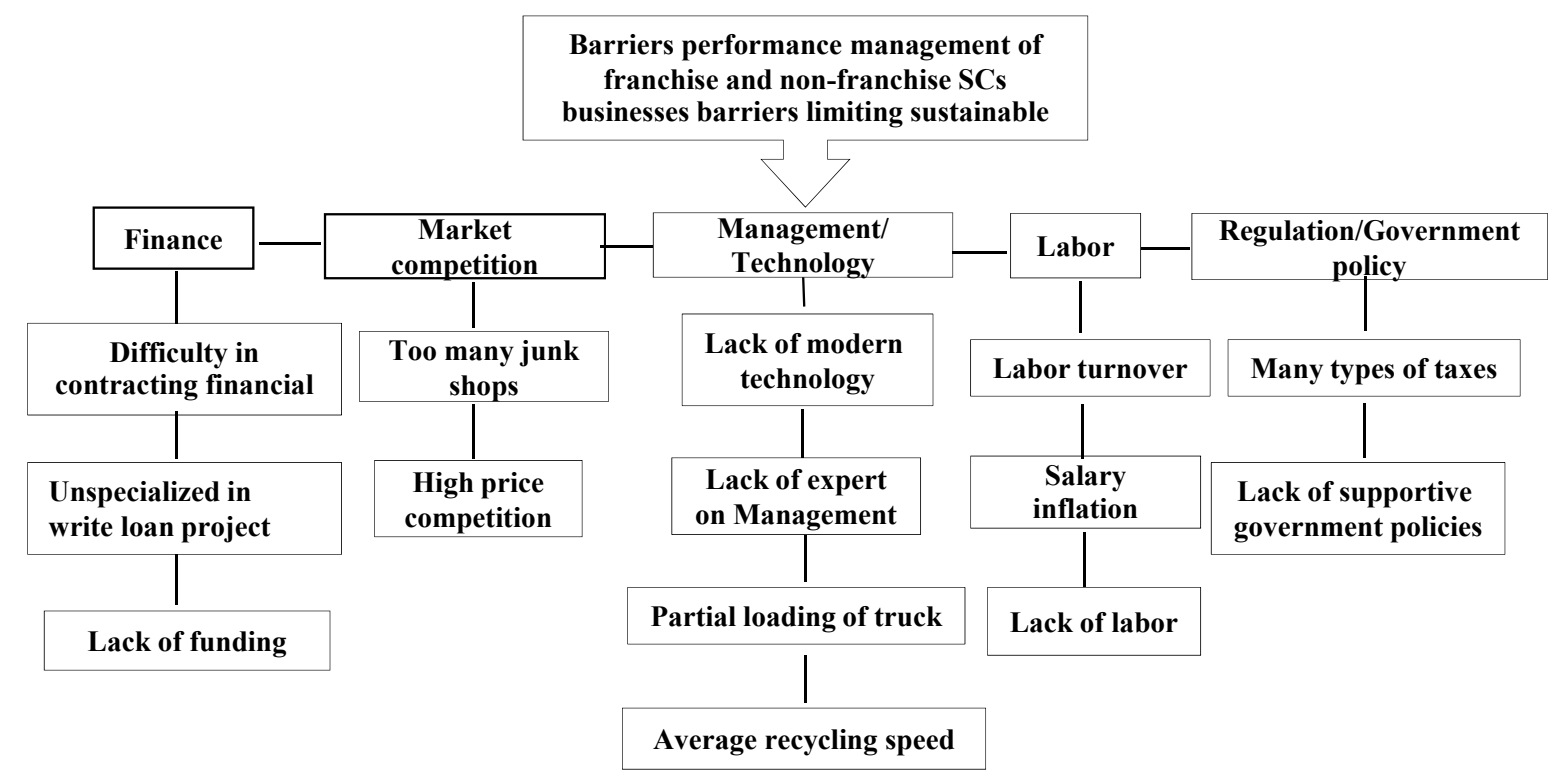




\section{Discussions}

This study examines RL practices in a developing country, Thailand. From the investigation, it was found that cooperative-like SCs franchises perceived that their waste management practices were technologically advanced and had no environmental impacts on nearby areas. Economically, they are adaptive to changes in business, access to transportation networks and alterations in business plans. Furthermore, they are trusted by customers. Cooperative-like franchises have very high social involvement. Non-cooperative SCs perceive that they have lower impacts on nearby areas and are trusted by customers. They are less competitive on a technological level.

The main barriers affecting RL businesses involved in waste management fall into several categories. These are as follows. (1) Financial difficulty: in general, individual firms within the informal sector, especially non-franchise SCs, have been barely trusted by financial institutions/banks with regard to granting them a loan for buying machinery or investment that would achieve economies of scale as mentioned by [15]. (2) Market competitiveness: this investigation found that the expansion of many small, manual separation centers affected market share, as they have to compete against each other in recyclable material pricing, leading to reduced production if investment in expansion was not sufficient at a particular time. (3) Managerial issues explored that the lack of modern technology, not economies of scale, on the transportation of waste and reverse logistics experts and the findings are similar to that of previous study of [33]. Most of the non-franchise firms require information and knowledge and modern technology to compact waste, which would enable a reduction in transportation costs in line with previous studies $[25,30,32]$. (4) Labor concerns: there were always only temporary workers due to the type of hard work and the unfavorable working environment (working in a dirty place and with odors). Lacking permanent labor leads to a lack of well-trained and skilled workers, which ultimately causes the instability in a number of companies [23,28]. (5) Regulation problems: there was a high tax burden, and many type of taxes were collected by the government, as it is considered an unfriendly business by the nearby area, due to its dirtiness. A lack of supportive government policies was observed, which is in the line with a previous study [33].

From the analysis, it has been observed that many things show that the cooperative-like franchise practice model has application in waste management practices. Cooperative-like franchises operate with the slogan, "Waste is Gold". This is much better than that of the non-franchise SCs. Franchisee-franchisor contracts have standards to ensure quality of service. Under a franchise system, managers must participate in multi-day waste management training courses. The program emphasizes RL process starting from waste collection and separation until transportation to the end user. It also covers plant layout, waste-buying and waste-selling methods. The franchisor provides information to franchisees daily about material prices and price trends, as well as providing consultation on specific issues. Such knowledge is important to franchisees, enabling them to improve their skills in collecting and separating different types of waste. Franchisees are required to pay a fee for the franchisor's brand and logo. Franchisors usually set the daily price for various types of waste. As depicted in Figure 5, a franchisee can sell waste directly to the franchisor or send the waste to a recycling center under the franchisor's brand. Through cooperation, there is potential for larger volume buying and selling of waste. Bargaining power can be increased and better prices received for recyclable materials. Collaboration among franchisees is possible through exchange of information, cooperative buying and sharing of best 
practices. Furthermore, information can be shared with society by cooperating with schools, communities and municipalities. In this way, training programs about collection and separation of wastes from various sources can be used to encourage more people to collect waste and reduce operating costs.

Figure 5. Franchise model practice of RL of waste management.

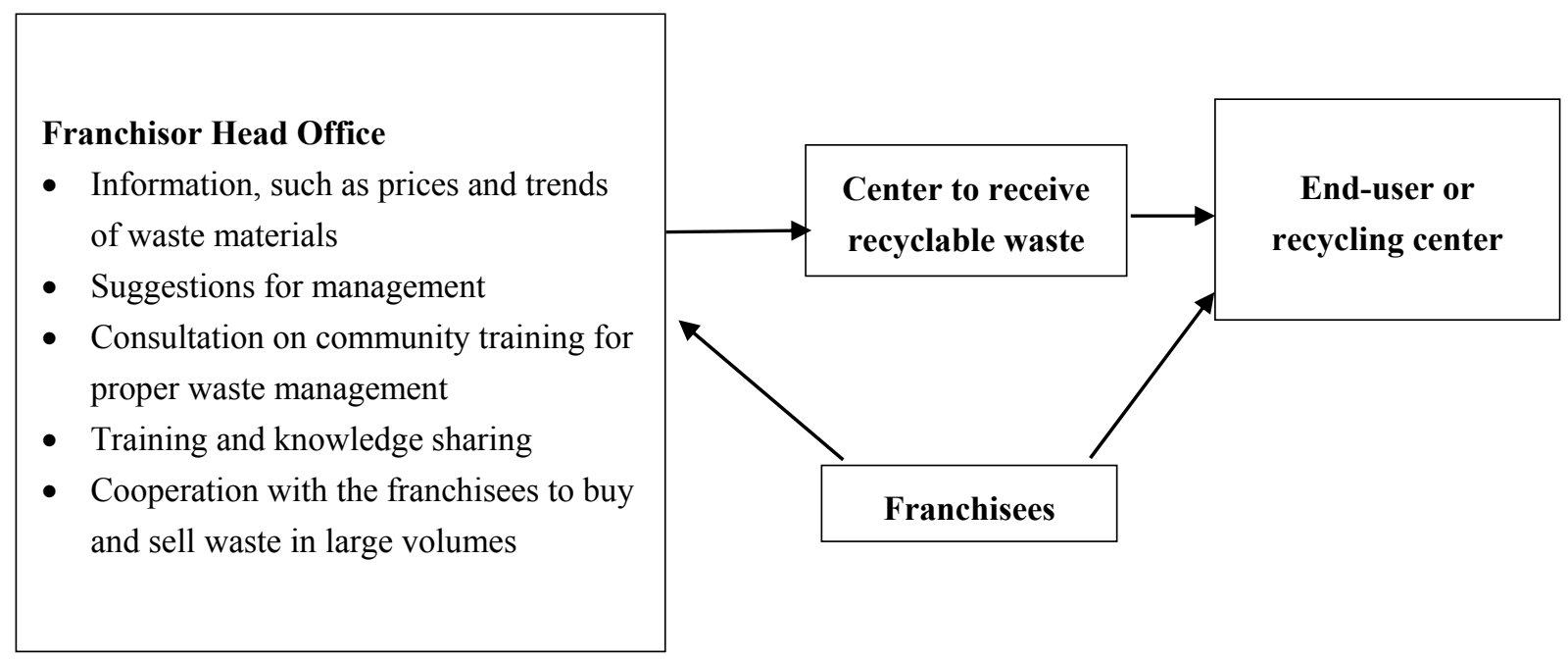

\section{Conclusions}

RL practices in Thailand are mostly performed by an informal sector that can be classified as downstream, middle stream and upstream. Waste separated from the source can reduce the costs and increase the benefits to the RL system; while upstream or end users need continuity of recyclable waste, waste cleanliness and correct sorting of raw material in production processes. SCs play an important role in RL systems through managing waste from its source to end users. The success of RL of waste management can be achieved through an increased amount of waste utilization. From investigation of factors influencing the perceptions of cooperative-like franchise practices, it is seen that cooperation brings more benefits and organization than non-franchise activities in RL practice. Non-franchise SCs, who make up the majority of SCs in Thailand, should improve worker skills, technology and economies of scale through training, cooperation and development of information systems. Improvement in the RL practices can sustain recycling activities, as well as training programs for reverse logistics experts and supportive policies from government to enhance recycling practices in the country. Further studies at the micro-level could include evaluation of all streams in RL systems for each type of recyclable waste. A cost-benefit analysis should be done to minimize costs and maximize revenues for each recyclable waste or stream and through employing a comprehensive optimization model. Furthermore, stakeholder and location network for each type of waste should be considered.

\section{Acknowledgments}

The authors would like to express their gratitude to the Asian Institute of Technology, Thailand, for providing funds for Ph.D. and conducting this research. The authors would also like to thank all respondents who have provided the necessary data required for this research. 


\section{Author Contributions}

Research was designed by Sumalee Pumpinyo and Vilas Nitivattananon. Field surveys, data compilation and analyses were conducted by Sumalee Pumpinyo; however, the manuscript writing was done by the authors collaboratively.

\section{Appendix}

Table A1. Characteristics of SCs.

\begin{tabular}{|c|c|c|c|}
\hline & Non-franchise & Franchise & Total \\
\hline \multicolumn{4}{|l|}{ Amount of waste buy and sale per day } \\
\hline Less than 10 ton/day & $46(46.9 \%)$ & $2(2.0 \%)$ & $48(49.0 \%)$ \\
\hline 10-30 ton/day & $25(25.5 \%)$ & $15(15.3 \%)$ & $40(40.8 \%)$ \\
\hline More than 30 ton/day & $3(3.1 \%)$ & $7(7.1 \%)$ & $10(10.2 \%)$ \\
\hline \multicolumn{4}{|l|}{ Investment } \\
\hline Less than 5 million baht & $50(51.0 \%)$ & $7(7.1 \%)$ & $57(58.2 \%)$ \\
\hline 5-30 million Baht & $20(20.4 \%)$ & $13(13.3 \%)$ & $33(33.7 \%)$ \\
\hline More than 30 million Baht & $4(4.1 \%)$ & $4(4.1 \%)$ & $8(8.2 \%)$ \\
\hline \multicolumn{4}{|l|}{ Employee } \\
\hline $1-10$ worker & $37(37.8 \%)$ & $3(3.1 \%)$ & $40(40.8 \%)$ \\
\hline $11-50$ & $36(36.7 \%)$ & $20(20.4 \%)$ & $56(57.1 \%)$ \\
\hline More than 50 & $1(1 \%)$ & $1(1 \%)$ & $2(2.0 \%)$ \\
\hline \multicolumn{4}{|l|}{ Cooperation } \\
\hline SMEs & $0(0 \%)$ & $7(7.1 \%)$ & $7(7.1 \%)$ \\
\hline Department of Industrial Promotion & $3(3.1 \%)$ & $3(3.1 \%)$ & $6(6.1 \%)$ \\
\hline The Federation of Thai Industries & $0(0 \%)$ & $3(3.1 \%)$ & $3(3.1 \%)$ \\
\hline Pollution Control Department & $46(46.9 \%)$ & $2(2.0 \%)$ & $48(49 \%)$ \\
\hline None & $25(25.5 \%)$ & $9(9.2 \%)$ & $34(34.7 \%)$ \\
\hline \multicolumn{4}{|l|}{ Sex } \\
\hline Male & $42(42.9 \%)$ & $12(12.2 \%)$ & $54(55.1 \%)$ \\
\hline Female & $32(32.7 \%)$ & $12(12.2 \%)$ & $44(44.9 \%)$ \\
\hline \multicolumn{4}{|l|}{ Age } \\
\hline Less than 30 & $7(7.1 \%)$ & $0(0 \%)$ & $7(7.1 \%)$ \\
\hline $31-40$ & $22(22.4 \%)$ & $8(8.2 \%)$ & $30(30.6 \%)$ \\
\hline $41-50$ & $28(28.6 \%)$ & $14(14.3 \%)$ & $42(42.9)$ \\
\hline $51-60$ & $16(16.3 \%)$ & $1(1.0 \%)$ & $17(17.3 \%)$ \\
\hline More than 60 & $1(1.0 \%)$ & $1(1.0 \%)$ & $2(2.0 \%)$ \\
\hline \multicolumn{4}{|l|}{ Education } \\
\hline Primary & $18(18.4 \%)$ & $1(1.0 \%)$ & $19(19.4 \%)$ \\
\hline Junior secondary & $1(1.0 \%)$ & $0(0 \%)$ & $1(1 \%)$ \\
\hline Senior secondary & $3(3.1 \%)$ & $0(0 \%)$ & $3(3.1 \%)$ \\
\hline Commerce & $26(26.5 \%)$ & $2(2.0 \%)$ & $28(28.6 \%)$ \\
\hline Bachelor & $22(22.4 \%)$ & $13(13.3 \%)$ & $35(35.7 \%)$ \\
\hline Master or higher & $4(4.1 \%)$ & $8(8.2 \%)$ & $12(12.2 \%)$ \\
\hline
\end{tabular}




\section{Conflicts of Interest}

The authors declare no conflict of interest.

\section{References}

1. Rogers, D.; Tibben-Lembke, R. An examination of reverse logistics practices. J. Bus. Logist. 2001, 22, 129-148.

2. Stock, J.R.; Speh, T.W.; Shear, H.W. Many happy (product) returns. Harv. Bus. Rev. 2002, 80, 16-17.

3. Pohlen, T.L.; Farris, M.T. Reverse logistics in plastics recycling. Inter. J. Phys. Distrib. Logist. Manag. 1992, 22, 35-47.

4. Pollution Control Department. State of Thailand Pollution Report 2011; Pollution Control Department: Bangkok, Thailand, 2011.

5. Achapan, I. Recycling as Habitual Behavior: The Impact of Habit on Household Waste Recycling Behavior in Thailand. Asian Soc. Sci. 2012, doi:10.5539/ass.v8n6p74.

6. The Thai Pulp and Paper Industries Association. 2013 Directory; Thai Pulp and Paper Industries Association: Bangkok, Thailand, 2013.

7. Wilson, D.C.; Velis, C.; Cheeseman, C. Role of informal sector recycling in waste management in developing countries. Habitat. Int. 2006, 30, 797-808.

8. Stock, J.R. Reverse Logistics. Council of Logistics Management: Oak Brook, IL, USA, 1992.

9. Fleischmann, M.; Krikke, H.R.; Dekker, R.; Flapper, S.D.P. A characterization of logistics networks for product recovery. Omega 2000, 28, 653-666.

10. Thierry, M.C.; Salomon, M.; van Nunen, J.; van Wassenhove, L.N. Strategic issues in product recovery management. Calif. Manag. Rev. 1995, 37, 114-135.

11. De Brito, M.P.; Dekker, R. Reverse Logistics-A framework. Econom. Inst. Rep. EI 2002, 38, 1-19.

12. Meade, L.; Sarkis, J.; Presley, A. The theory and practice of reverse logistics. Inter. J. Logist. Sys. Manag. 2007, 3, 56-84.

13. Louwers, D.; Kip, B.J.; Peters, E.; Souren, F.; Flapper, S.D.P. A facility location allocation model for reusing carpet materials. Comp. Ind. Eng. 1999, 36, 855-869.

14. Heng, N.; Laptaned, U.; Mehrdadi, N. Recycling and reuse of household plastics. Int. J. Environ. Resour. 2008, 2, 27-36.

15. Wongthatsanekorn, W. A goal programming approach for plastic recycling in Thailand. World Acad. Sci. Eng. Tech. 2009, 49, 513-518.

16. Chowdhury, M.; Paul, H.; Das, A. The impact of top management commitment on total quality management practice: An exploratory study in the Thai government industry. Glob. J. Flex. Syst. Manag. 2007, 8, 17-29.

17. Pollution Control Department. State of Thailand Pollution Report 2012; Pollution Control Department: Bangkok, Thailand, 2012.

18. Yamane, T. Statistics, An Introductory Analysis, 2nd ed.; Harper and Row: New York, NY, USA, 1967.

19. Miah, M.A.Q.; Miẏa, M.A.K.; Simpson, H.R. Applied Statistics: A Course Handbook for Human Settlements Planning; Asian Institute of Technology: Bangkok, Thailand, 1993. 
20. Samonporn, S.; Vilas, N. Assessment of factors influencing the performance of solid waste recycling programs. Resour. Conservat. Recycl. 2008, 53, 45-56.

21. Rousta, K.; Ekström, K.M. Assessing Incorrect Household Waste Sorting in a Medium-Sized Swedish City. Sustainability 2014, 5, 4349-4361.

22. Jahre, M. Household waste collection as a reverse channel. Int. J. Phys. Distrib. Logist. Manag. 1995, 25, 39-55.

23. Rogers, D.; Tibben-Lembke, R. Going Backwards: Reverse Logistics Trends and Practices; Reverse Logistics Executive Council Press: Pittsburgh, PA, USA, 1999.

24. Klang, A.; Vikman, P.A.; Brattebo, H. Sustainable management of demolition waste: An integrated model for the evaluation of environmental, economic and social aspects. Res. Conservat. Recycl. 2003, 38, 317-334.

25. De Brito, M.P.; Carboneb, V.; Blanquart, C.M. Towards a sustainable fashion retail supply chain in Europe: Organizations and performance. Int. J. Prod. Econ. 2008, 114, 534-553.

26. Pati, R.K.; Vrat, P.; Kumar, P. A goal programming model for paper recycling system. Omega 2008, $36,405-417$.

27. Daugherty, P.; Richey, R.; Hudgens, B.; Autry, C. Reverse logistics in the automobile aftermarket industry. Int. J. Logis. Manag. 2003, 14, 49-62.

28. Ravi, V.; Ravi, S.; Tiwari, M.K. Productivity improvement of a computer hardware supply chain. Int. J. Prod. Perform. Manag. 2005, 3, 239-255.

29. Ramirez, A.M. Product return and logistics knowledge: Influence on performance of the firm. Transport. Res. E Logist. Transport. Rev. 2012, 48, 1137-1151.

30. Shih, K.H.; Chang, C.J.; Binshan, L. Assessing knowledge creation and intellectual capital in the banking industry. J. Intel. Cap. 2010, 11, 74-89.

31. Wadhwa, S.; Madaan, J. Conceptual framework for knowledge management in reverse enterprise systems. J. Knowl. Manag. Pract. 2007, 8, 1-22.

32. Kumar, S.; Putnam, V. Cradle to cradle: Reverse logistics strategies and opportunities across three industry sectors. Int. J. Prod. Econ. 2005, 115, 305-315.

33. Abdulrahman, M.D.; Gunasekaran, A.; Subramanian, N. Critical barriers in implementing reverse logistics in the Chinese manufacturing sectors. Int. J. Prod. Econ. 2014, 147, 460-471.

(C) 2014 by the authors; licensee MDPI, Basel, Switzerland. This article is an open access article distributed under the terms and conditions of the Creative Commons Attribution license (http://creativecommons.org/licenses/by/4.0/). 